\title{
Intraoperative Cardiac Ultrasound Examination Using Vector Flow Imaging
}

Hansen, Kristoffer Lindskov; Pedersen, Mads Møller; Møller-Sørensen, Hasse; Kjaergaard, Jesper; Nilsson, Jens Christian; Lund, Jens Teglgaard; Jensen, Jørgen Arendt; Bachmann, Michael Bachmann

Published in:

Ultrasonic Imaging

Link to article, DOI:

$10.1177 / 0161734613505552$

Publication date:

2013

Document Version

Publisher's PDF, also known as Version of record

Link back to DTU Orbit

Citation $(A P A)$ :

Hansen, K. L., Pedersen, M. M., Møller-Sørensen, H., Kjaergaard, J., Nilsson, J. C., Lund, J. T., Jensen, J. A., \& Bachmann, M. B. (2013). Intraoperative Cardiac Ultrasound Examination Using Vector Flow Imaging. Ultrasonic Imaging, 35(4), 318-322. https://doi.org/10.1177/0161734613505552

\section{General rights}

Copyright and moral rights for the publications made accessible in the public portal are retained by the authors and/or other copyright owners and it is a condition of accessing publications that users recognise and abide by the legal requirements associated with these rights.

- Users may download and print one copy of any publication from the public portal for the purpose of private study or research.

- You may not further distribute the material or use it for any profit-making activity or commercial gain

- You may freely distribute the URL identifying the publication in the public portal 


\section{Ultrasonic Imaging}

Intraoperative Cardiac Ultrasound Examination Using Vector Flow Imaging Kristoffer Lindskov Hansen, Mads Møller Pedersen, Hasse Møller-Sørensen, Jesper Kjaergaard, Jens Christian Nilsson, Jens Teglgaard Lund, Jørgen Arendt Jensen and Michael Bachmann Nielsen

Ultrason Imaging 2013 35: 318

DOI: $10.1177 / 0161734613505552$

The online version of this article can be found at:

http://uix.sagepub.com/content/35/4/318
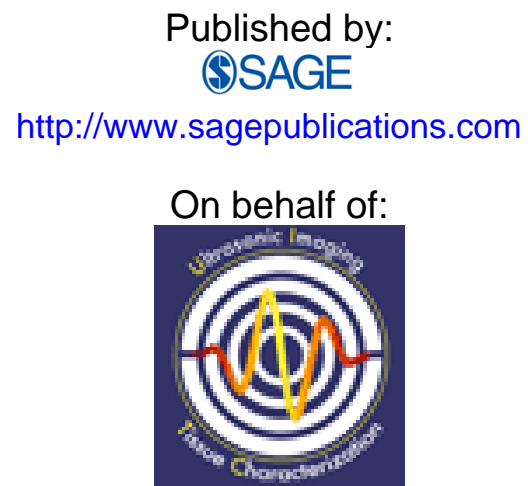

Ultrasonic Imaging and Tissue Characterization Symposium

Additional services and information for Ultrasonic Imaging can be found at:

Email Alerts: http://uix.sagepub.com/cgi/alerts

Subscriptions: http://uix.sagepub.com/subscriptions

Reprints: http://www.sagepub.com/journalsReprints.nav

Permissions: http://www.sagepub.com/journalsPermissions.nav

Citations: http://uix.sagepub.com/content/35/4/318.refs.html

>> Version of Record - Sep 30, 2013

What is This? 


\title{
Intraoperative Cardiac Ultrasound Examination Using Vector Flow Imaging
}

\section{Kristoffer Lindskov Hansen', Mads Møller Pedersen', Hasse Møller-Sørensen², Jesper Kjaergaard ${ }^{3}$, Jens Christian Nilsson $^{2}$, Jens Teglgaard Lund ${ }^{4}$, Jørgen Arendt Jensen ${ }^{5}$, and Michael Bachmann Nielsen'}

\begin{abstract}
Conventional ultrasound (US) methods for blood velocity estimation only provide onedimensional and angle-dependent velocity estimates; thus, the complexity of cardiac flow has been difficult to measure. To circumvent these limitations, the Transverse Oscillation (TO) vector flow method has been proposed. The vector flow method implemented on a commercial scanner provided real-time, angle-independent estimates of cardiac blood flow. Epicardiac and epiaortic, intraoperative US examinations were performed on three patients with stenosed coronary arteries scheduled for bypass surgery. Repeating cyclic beat-to-beat flow patterns were seen in the ascending aorta and pulmonary artery of each patient, but these patterns varied between patients. Early systolic retrograde flow filling the aortic sinuses was seen in the ascending aorta as well as early systolic retrograde flow in the pulmonary artery. In diastole, stable vortices in aortic sinuses of the ascending aorta created central antegrade flow. A stable vortex in the right atrium was seen during the entire heart cycle. The measurements were compared with estimates obtained intraoperatively with conventional spectral Doppler US using a transesophageal and an epiaortic approach. Mean differences in peak systole velocity of II\% and $26 \%$ were observed when TO was compared with transesophageal echocardiography and epiaortic US, respectively. In one patient, the cardiac output derived from vector velocities was compared with pulmonary artery catheter thermodilution technique and showed a difference of $16 \%$. Vector flow provides real-time, angle-independent vector velocities of cardiac blood flow. The technique can potentially reveal new information of cardiovascular physiology and give insight into blood flow dynamics.
\end{abstract}

\section{Keywords}

ultrasound, vector flow imaging, cardiac imaging, blood flow, Transverse Oscillation

\footnotetext{
'Department of Radiology, Rigshospitalet, Copenhagen University Hospital, Denmark

2Department of Cardiothoracic Anesthesiology, Rigshospitalet, Copenhagen University Hospital, Denmark

${ }^{3}$ Department of Cardiology, Rigshospitalet, Copenhagen University Hospital, Denmark

${ }^{4}$ Department of Cardiothoracic Surgery, Rigshospitalet, Copenhagen University Hospital, Denmark

${ }^{5}$ Center for Fast Ultrasound Imaging, DTU Elektro, Technical University of Denmark, Copenhagen, Denmark
}

\section{Corresponding Author:}

Kristoffer Lindskov Hansen, Department of Radiology, Rigshospitalet, Blegdamsvej 9, 2100 Copenhagen, Denmark.

Email: lindskov@gmail.com 


\section{Introduction}

The interaction between the blood and the heart, valves, and great vessels in the thoracic compartment creates a system, which generates complex flow patterns that are multidirectional, vortical, and with velocity changes throughout the cardiac cycle. ${ }^{1}$ Normal and pathological flow patterns in the thoracic cardiovascular system have been investigated for several decades using invasive and noninvasive techniques, as it is believed that analyzing the spatial and temporal distribution of blood flow can provide diagnostic and prognostic information. ${ }^{1}$

The two main modalities used noninvasively to visualize cardiac blood flow are magnetic resonance imaging (MRI) and ultrasound (US). MRI using phase contrast (MRI PC) provides a vector flow map of the blood flow characterized by direction and velocity, ${ }^{2-5}$ and three-dimensional (3D) cardiac blood flow has been thoroughly described. ${ }^{6-12}$ Echocardiography is clinically far more used than MRI PC as it can be used bedside and is a fast, cheap, and reliable estimator for cardiac flow. ${ }^{13}$ US imaging is also frequently used during cardiac surgery, and transesophageal echocardiography (TEE) is becoming an integrated tool for circulatory evaluation in the operating room. In the American Society of Anesthesiologists guidelines and the European Society of Cardiologist guidelines, it is recommended that TEE should be used in adult patients undergoing surgery to the thoracic aorta, at coronary artery bypass graft surgery, and in specific types of major surgery. ${ }^{14,15}$ For example, TEE is used for assessing the severity of valve stenosis or valve insufficiency and septal defects by measuring spectral Doppler-derived blood velocities. However, due to the inherent limitation of conventional Doppler systems with one-dimensional (1D) and angle-dependent estimates, the complexity of cardiac flow has been difficult to measure. ${ }^{16,17}$

Several authors have tried to get around the angle dependency in conventional Doppler systems, and efforts have been made to create a vector flow US system. ${ }^{18-21}$ Recent studies include Nyrnes et al. who examined an approach called Blood Flow Imaging where in vivo blood speckle motion is visualized in arterial septal defects. ${ }^{22}$ Also Lovstakken et al. reported on a similar technique in a study concerning intraoperative assessment on blood flow patterns in coronary anastomoses $^{23}$ as well as Flynn et al. using plane wave transmission. ${ }^{24}$ The studies concern speckle-tracking methods with enhanced flow visualization but without any quantitative parameters provided. Pastorelli et al. reported on a multigated dual-beam method providing real-time, angle-independent vector velocity maps and validated it against a flow phantom. The method performs with a bias of $23 \%$, a frame rate of $6 \mathrm{~Hz}$ down to a maximum scanning depth of $1 \mathrm{~cm}$, due to the necessary beam crossing. ${ }^{25}$

Another promising method for US vector velocity estimation, Transverse Oscillation (TO), has been proposed by Jensen and Munk ${ }^{26-28}$ and tested in computer simulations and with flow phantoms. ${ }^{29}$ In vivo examples have been provided for blood flow in superficial vascular geometries $^{30,31}$ and it has been validated in vivo on healthy volunteers against MRI angiography ${ }^{32,33}$ and conventional spectral Doppler US. ${ }^{34}$

In this study, the TO method implemented on a conventional US scanner (Pro Focus 2202 UltraView, BK Medical, Herlev, Denmark) has been applied on epicardiac and epiaortic realtime vector flow examinations in three patients undergoing open-chest cardiac surgery. Examples of vector flow measurement of different cardiac sites are presented and compared with conventional Doppler US obtained with TEE and epicardiac US examination.

The TO method can potentially become a valuable tool in understanding cardiac flow in healthy and diseased persons. TO can be used as a tool for monitoring flow changes during, for example, valve surgery and repair of congenital heart diseases such as intracardiac shunts and coarctation of the aorta. In this study, three patients scheduled for open-chest bypass surgery 
were included. According to previous medical history and echocardiography, all three patients had normal cardiac function apart from stenosed coronary arteries.

The aim of this study was to investigate the feasibility of vector flow estimation in vivo directly on the heart during surgery to provide preliminary results concerning a qualitative description of the cardiac flow as well as quantitative measurements compared with TEE and conventional Doppler.

\section{Materials and Method}

This study was performed after approval by the Danish National Committee on Biomedical Research Ethics (No. H-2-2012-039). Three patients undergoing coronary bypass surgery (male: 67 years, female: 68 years, female: 79 years) with no history of valvular disease, atrial flutter or fibrillation, or septum defects entered the study after informed consent.

Scan sequences in Doppler mode of the ascending aorta were obtained initially with TEE carried out by an experienced and TEE-certified anesthesiologist. After standard sternotomy and before establishing of coronary bypass, epicardiac and epiaortic scan sequences of different cardiovascular sites were recorded with conventional Doppler US and TO. An experienced radiologist and cardiologist performed the epicardiac and epiaortic scans. For one patient, additional pulmonary artery thermodilution measurements were obtained and compared with volume flow measurements derived from TO estimates.

The basis for estimating the vector velocity with the TO method has been described previously. ${ }^{26-29}$ In brief, the TO method tracks scatterer motion along two orthogonal axes by emitting a pulse identical to conventional Doppler US. The motion in the axial direction is found exactly as in conventional Doppler US. An oscillation in the transverse direction is created by changing the sensitivity of the receiving elements, and the transverse velocity component is found from the frequency content of this oscillation. The two-dimensional (2D) vector velocity of the moving scatterer is found by combining the velocity components along the two axes.

A conventional US scanner (Pro Focus 2202 UltraView, BK Medical) and a linear transducer (Type: 8670, BK Medical) under sterile settings were used to record epiaortic and epicardiac scan sequences. The TO method is implemented so that real-time estimation of vector flow is achieved with a frame rate of 15 frames per second. The center frequency of TO emissions was $5 \mathrm{MHz}$. The pulse repetition frequency (PRF) varied from 1.0 to $11.0 \mathrm{kHz}$ depending on the blood flow velocities and 16 emissions were used per estimate. The angle-independent vector velocities are displayed real time on the B-mode image as colored pixels given by a $2 \mathrm{D}$ color bar defining flow direction and velocity magnitude. To facilitate interpretation of the vector velocity estimation, small arrows are superimposed on to the color flow map. These arrows illustrate the momentary changes in blood flow by indicating flow direction and velocity magnitude. Maximum scan depth for vector flow is approximately $5 \mathrm{~cm}$ due to the transducer setup available.

In this study, examinations were acquired of the ascending aorta and pulmonary artery in short- and long-axis views and of the right atrium in long-axis view. Scan sequences were recorded irrespective of the respiratory cycle. ${ }^{35}$ For each scan sequence, Doppler gain, PRF, and wall filtering were optimized for flow imaging. Even though the vector flow estimation is achieved and displayed in real-time, no quantification of velocities is available on the scanner. Thus, scan sequences were stored and analyzed off-line using Matlab (Mathworks, Natick, MA, USA). Multigating was achieved with range-gates placed central and wall-near in the lumen to obtain the velocity distribution at different locations in the vessel simultaneously. Retrograde flow was assigned with a minus. Volume flow estimation was found from a line of angle-corrected estimates perpendicular to vessel boundaries by assuming circular vessel geometry and rotationally symmetric flow. Furthermore, from vector velocities were calculated the rotational 
frequency along with flow lines for the secondary flow in the ascending aorta. Further details about the measurement setup and post-processing are described by Pedersen et al., ${ }^{34,36}$ and details of the volume flow calculation from vector estimates are described by Hansen et al. ${ }^{33}$

TEE scans were performed with a Philips X7-2t transducer and a Philips iE33 scanner (Philips Medical Systems, Andover, MA, USA). Scan parameters were adjusted for flow imaging, and scan sequences were stored for evaluation. A comprehensive TEE examination was performed according to guidelines by the European Society of Cardiology, with special focus on central flow downstream of the aortic valve..$^{15}$

Furthermore, for one patient, a 7.5F pulmonary artery catheter thermodilution (PAC TD) catheter (Swan-Ganz Oximetry TD catheter, Baxter Edwards Critical Care, Irvine, CA, USA) was inserted, and the cardiac output measured by PAC TD was determined by the HP-Philips M1012A Cardiac Output Module (Hewlett Packard, Boeblingen, Germany).

For each method, TO, TEE, and epiaortic US, a cine loop encompassing on average 6.3 heart cycles (range $=3-8$ ), were used for calculation of peak systolic velocities. No studies of repeatability of the measurements of the three methods were conducted due to the limited time available during operation. The repeatability of the measurements can, however, be roughly determined by studying the similarities between heartbeats. The cardiac blood velocity measurements obtained with TO, TEE, and epiaortic US were recorded within a period of 10 minutes. Measurements for the volume flow estimation obtained with PAC TD and TO were recorded simultaneously.

\section{Results}

The ascending aorta was examined in a long-axis view with the valve and aortic sinuses visible. Scan sequences of the ascending aorta downstream of aortic sinuses in a short-axis view were also obtained. Central flow downstream of the valve was measured with TEE and epiaortic Doppler examination for comparison.

An antegrade jet exiting the left ventricle was formed between the valve cusps in systole. The jet was for two patients skewed toward the outer curvature and for one patient skewed toward the inner curvature. For all three patients, an accompanying retrograde flow along the vessel walls was seen during the entire systole with well-defined vortical flow formation in the aortic sinuses. The vortices moved along the vessel wall to curve centrally toward the valve. The systolic retrograde flow for each patient had a repeating cyclic pattern. However, variation was observed between the three patients with the systolic retrograde flow going along the inner, the outer, or both curvatures. An example is given in Figure 1 along with multigating, where range-gates placed central and wall-near in the vessel simultaneously provided the velocity distributions over time.

In diastole, the retrograde flow was reflected on the closed valve cusps to create antegrade flow centrally while slow moving vortices were formed in the aortic sinuses (Figure 2). The secondary flow obtained in a short-axis view of the ascending aorta was examined in two patients. In systole, a well-defined clockwise secondary flow was visualized for both patients (Figure 3) while no secondary flow was visible in diastole. For the depicted frame in Figure 3, additional flow lines are shown and the frequency of the rotation was found to be $3.5 \mathrm{~Hz}$.

For one patient, the cardiac movements were so pronounced that velocity estimation using conventional epiaortic Doppler was hindered. Thus, for two patients, a preliminary quantitative comparison between TO and conventional US was carried out. Maximum velocity in systole given in $\mathrm{cm} / \mathrm{s}$ in the ascending aorta was found as an average of several cardiac cycles for all three modalities. For TEE, no angle correction was performed as flow was mainly toward the transducer; for epiaortic conventional Doppler US, angle correction was employed; and 

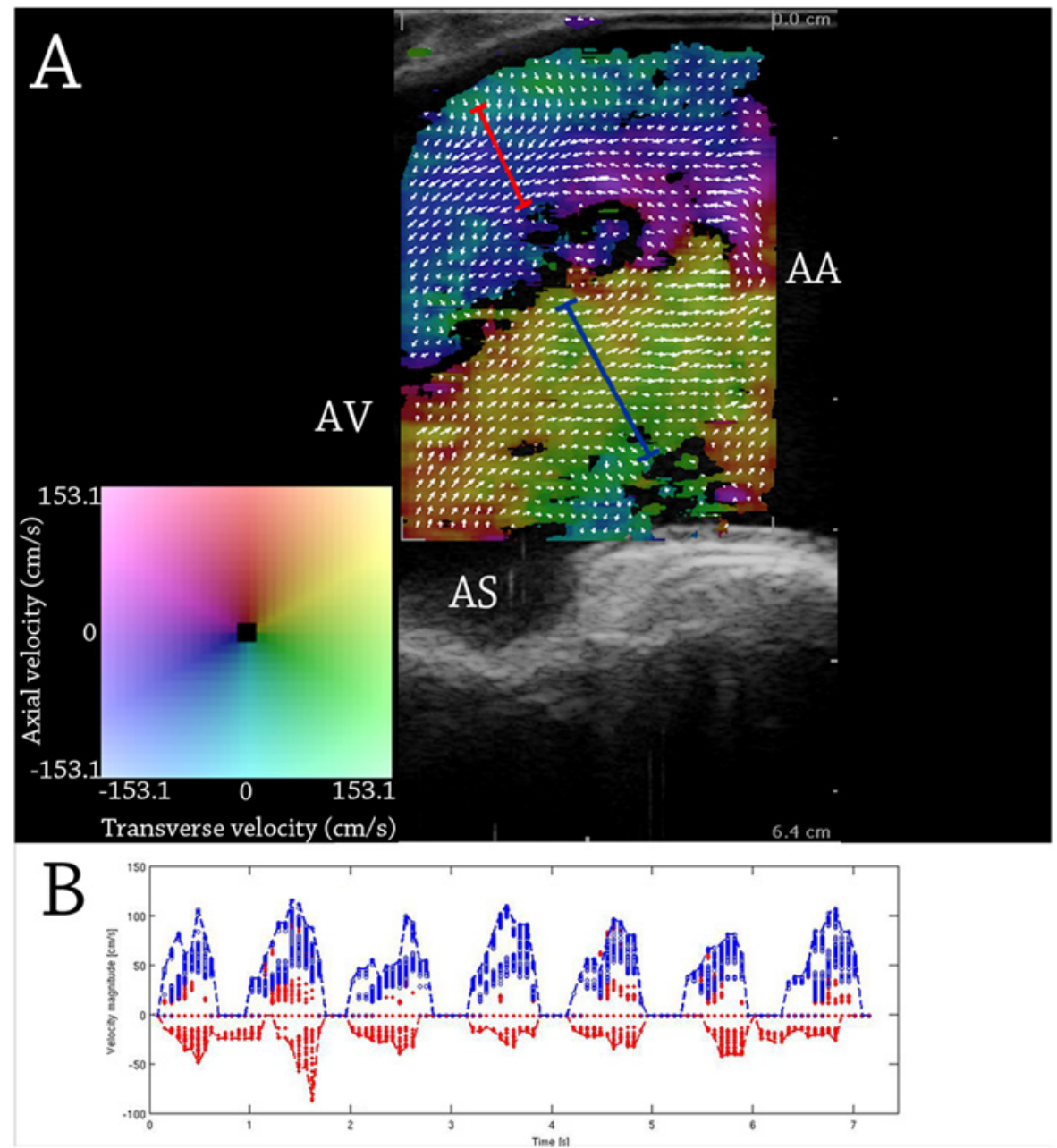

Figure I. In the ascending aorta, a central, antegrade jet during systole is seen with retrograde flow along vessel boundaries. Blue and red velocity distributions depicted in $(B)$ are taken from the corresponding range-gates in $(A)$. The velocities are obtained simultaneously by multigating. $A A=$ ascending aorta; $\mathrm{AV}=$ aortic valve; $\mathrm{AS}=$ aortic sinus.

for TO, estimates were derived from angle-independent vector velocities, and thus, without angle correction. The averaged maximum systolic velocities along with the range of maximum systolic velocities within each recording are given in Table 1 . The mean difference of TO compared with TEE and epiaortic US was $11 \%$ and $26 \%$, respectively. Furthermore, cardiac output was measured from angle-corrected vector estimates of TO from a scan sequence of the ascending aorta in longaxis view (Figure 4) and compared with PAC TD. The cardiac output and stroke volume measured with TO were $3.2 \mathrm{~L} / \mathrm{min}$ and $57.1 \mathrm{~mL} /$ stroke, while cardiac output and stroke volume measured with PAC TD were $3.8 \mathrm{~L} / \mathrm{min}$ and $63.5 \mathrm{~mL} /$ stroke, that is, the differences between TO and PAC TD when measuring cardiac output and stroke volume were $16 \%$ and $10 \%$, respectively. 


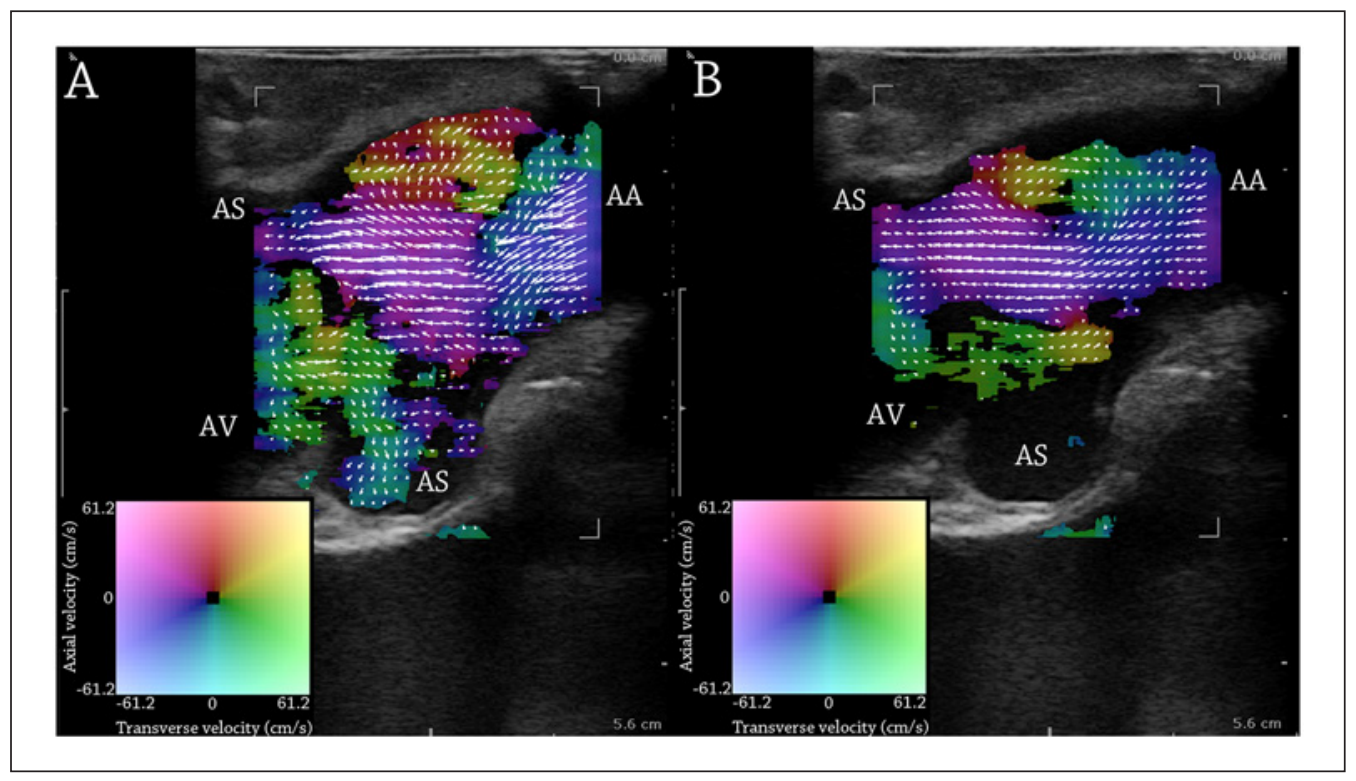

Figure 2. In early diastole, the retrograde flow in the ascending aorta was reflected on the closed valve cusps and created vortices in the aortic sinuses (A). In late diastole, the retrograde flow created welldefined antegrade flow (B). $A S=$ aortic sinus; $A A=$ ascending aorta; $A V=$ aortic valve.

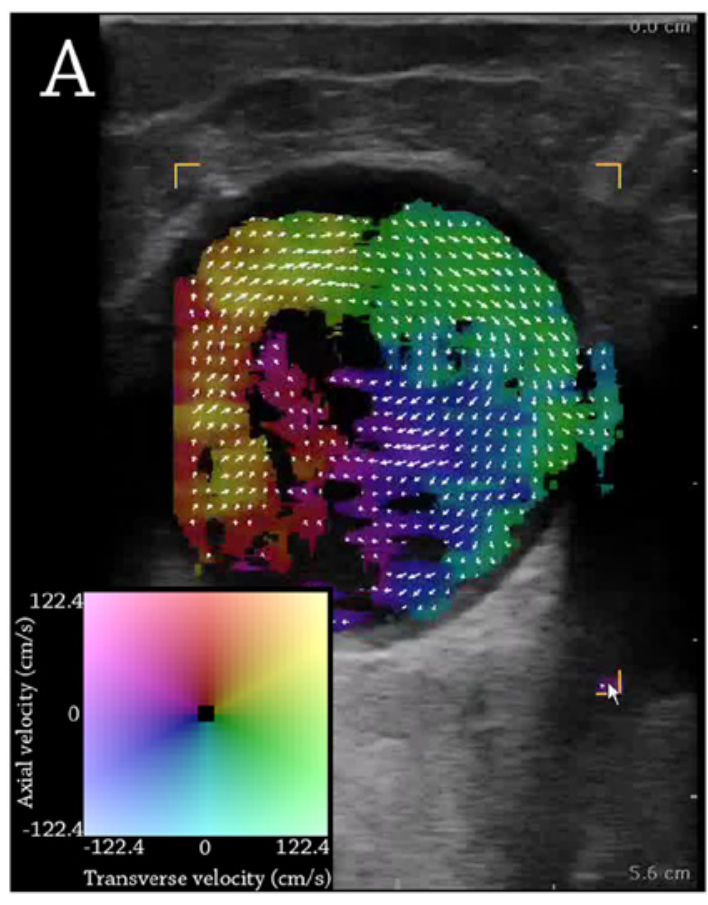

\section{B}

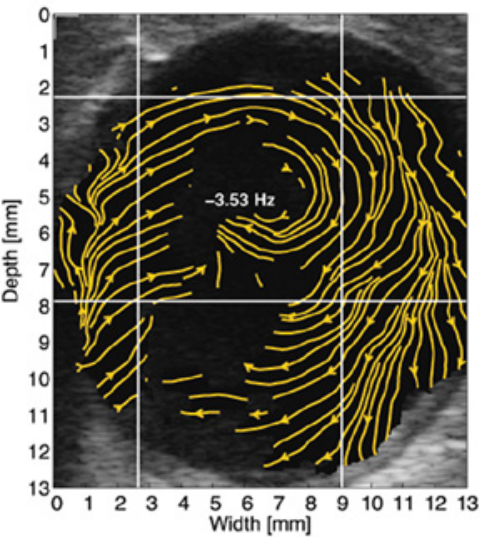

Figure 3. A well-defined clockwise secondary flow during systole is shown in the ascending aorta in (A). Flow lines along with the rotational frequency are given in (B). 
Table I. Mean Maximum Systolic Velocities (and Range) Obtained in Two Patients with TO, TEE, and Epiaortic US.

\begin{tabular}{lccccc}
\hline Patient (No.) & TO $(\mathrm{cm} / \mathrm{s})$ & TEE $(\mathrm{cm} / \mathrm{s})$ & $\begin{array}{c}\text { Epiaortic US } \\
(\mathrm{cm} / \mathrm{s})\end{array}$ & $\begin{array}{c}\text { TEE-TO } \\
(\mathrm{cm} / \mathrm{s})\end{array}$ & $\begin{array}{c}\text { Epiaortic US-TO } \\
(\mathrm{cm} / \mathrm{s})\end{array}$ \\
\hline 1 & $110(95-120)$ & $110(95-115)$ & $140(130-170)$ & 0 & 30 \\
2 & $85(60-95)$ & $115(115-115)$ & $110(105-115)$ & 30 & 25 \\
\hline
\end{tabular}

TO = Transverse Oscillation; TEE = transesophageal echocardiography; US = ultrasound.

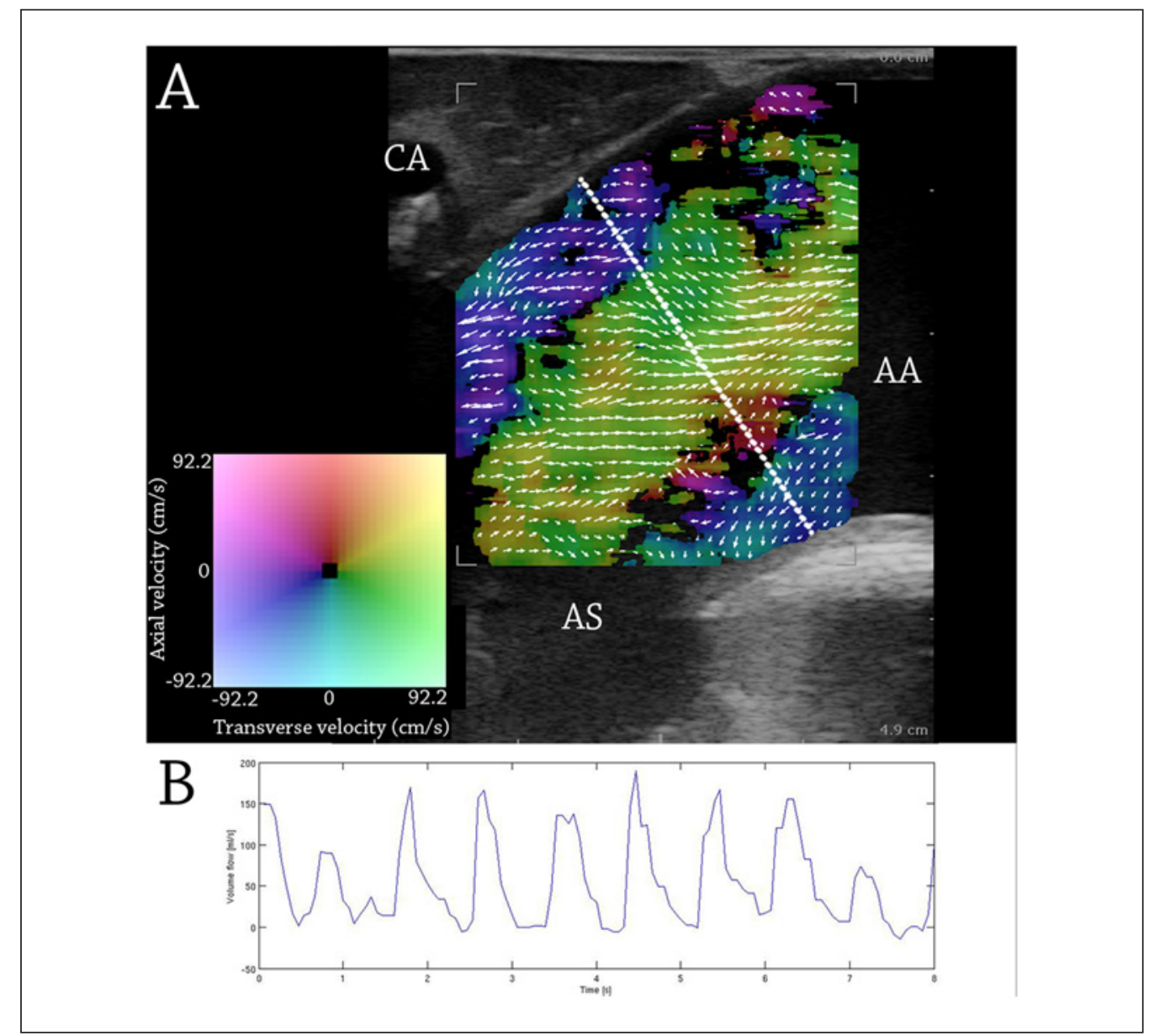

Figure 4. In (A), the ascending aorta is depicted with flow in the systolic phase. From vector velocities perpendicular to the dashed line in $(A)$, a volume flow curve is obtained as shown in (B). CA = coronary artery; $\mathrm{AA}=$ ascending aorta; $\mathrm{AS}=$ aortic sinus.

TO examination of the pulmonary artery showed blood flow with a flat profile in systole exiting the right ventricle. Retrograde vortical flow along the vessel walls was observed up- and downstream of the pulmonary valve during the entire systole (Figure 5). In diastole, the flow in the right ventricle was reflected on the closed valve cusps creating retrograde flow, while the 


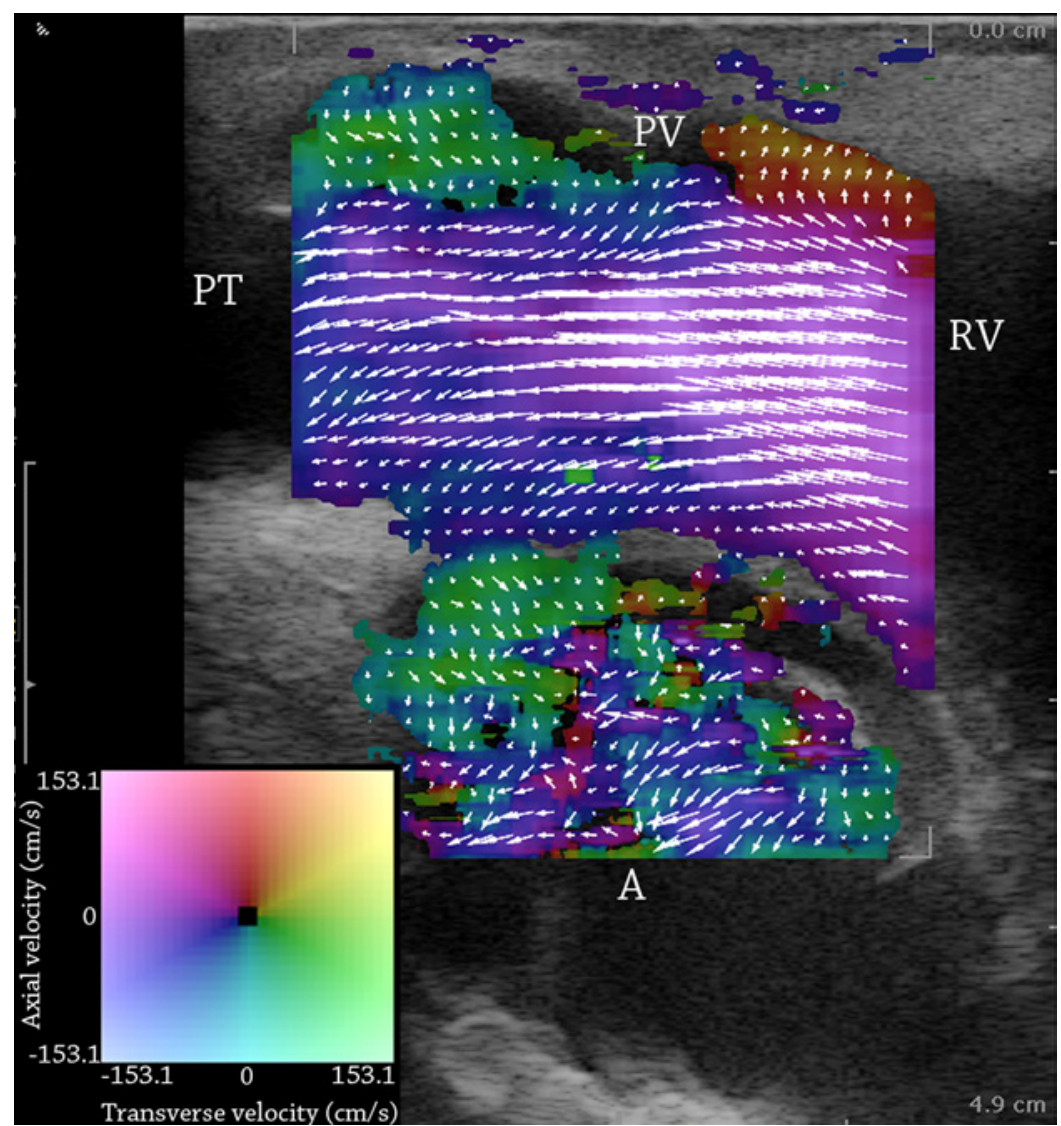

Figure 5. Vortices are formed up- and downstream of the pulmonary valve in the pulmonary artery during systole. The valve cusps are not visible due to blooming artifacts. $\mathrm{PV}=$ pulmonary valve; $\mathrm{PT}=$ pulmonary trunk; $\mathrm{RV}=$ right ventricle; $\mathrm{A}=$ aorta.

flow downstream of the valve primarily was antegrade created by wall-near retrograde flow reflected on the closed valve cusps (not shown).

For one patient, the pulmonary artery was scanned in short-axis view. A short systolic vortical secondary flow pattern was seen. The direction was primarily clockwise; however, for some heartbeats, counterclockwise direction was seen as well.

Finally, the right atrium was examined for one patient. A steady vortex present in systole and diastole was visualized. The vortical flow ran along the superficial wall and returned along the deep wall of the atrium redirecting inflowing blood toward the tricuspid valve (Figure 6).

\section{Discussion}

The TO method provides real-time, angle-independent estimation of cardiac blood flow. In this study, the ascending aorta, pulmonary artery, and right atrium were examined with TO in three patients undergoing open-chest cardiac surgery. Arrows superimposed on a color flow map visualize the flow by displaying velocity and direction. Even though, the scan sequences are 


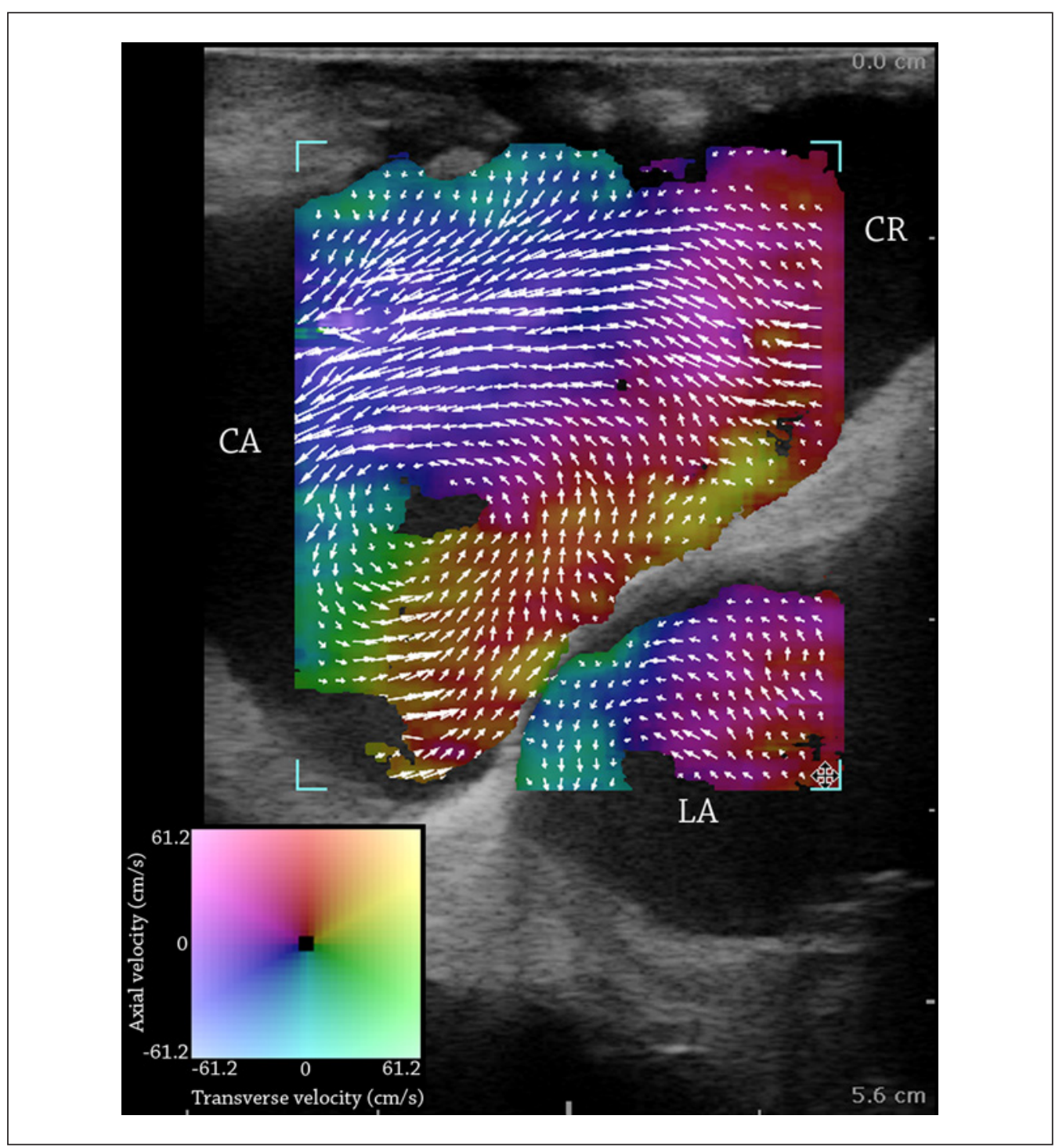

Figure 6. A stable clockwise vortex during systole and diastole is found in the right atrium. The tricuspid valve is to the left of the image. Notice the counterclockwise rotational flow in the left atrium found below the right atrium. $C R=$ cranial direction; $C A=$ caudal direction; LA = left atrium.

primarily treated as qualitative estimates as in conventional color Doppler, there are quantitative data to every point within the color box with TO estimation. Therefore, measurements such as angle-independent velocity estimation, volume flow, and multigating are achievable with vector flow estimation obtained with TO.

To the authors' knowledge, this is the first article presenting results of real-time vector flow imaging using US of the ascending aorta, the pulmonary artery, and the right atrium. As TO has been implemented on a commercial scanner, it was possible to acquire TO recordings directly on the heart under sterile settings. The sites were chosen due to limitation of the TO method as maximum scan depth is approximately $5 \mathrm{~cm}$. Scanning directly on the heart reduces the distance to the 
cardiac blood flow; however, for one patient, the movements of the heart were so pronounced that slow diastolic flow estimation with $\mathrm{TO}$ and spectral flow estimation with conventional Doppler were hindered as wall movements obscured the blood flow.

Vector flow estimation of aortic flow has been investigated previously with MRI PC. 1,6-8,11,37 As vector estimates from MRI PC are found from an averaged cardiac cycle using electrocardiographic (ECG) gating over a long acquisition time, ${ }^{38}$ beat-to-beat variation has not been addressed previously. Moreover, the spatial resolution in MRI PC is approximately $2 \mathrm{~mm}^{38}$ while TO provides a spatial isotropic resolution of approximately $1 \mathrm{~mm} .{ }^{31}$

TO showed that repeating cyclic patterns were reproducible from beat-to-beat for individual patients, but patterns between patients were significantly different. The latter observation is in concordance with Bogren and Buonocore reporting a late systolic retrograde flow differing in location and secondary flow in both directions among 16 volunteers. ${ }^{6}$ Other studies have shown reversed flow in late systole along inner curvature. ${ }^{8,11,12} \mathrm{TO}$ showed a retrograde flow starting in early systole for all three patients although with differing location in the lumen (Figures 1 and 4). Findings by Tortoli et al. using a multigating US system indicated a wall-near retrograde flow during the entire systole as seen in this study. ${ }^{39}$ Furthermore, common for the three patients was filling of the aortic sinuses with the retrograde flow. This flow formed from early systole vortical flow formations, creating an effective closing mechanism for the aortic valve. The vortices continued into the diastole forming antegrade flow on the closed valve cusps (Figure 2). Kvitting et al. reported vortical flow formation in aortic sinuses after peak systole in healthy volunteers. ${ }^{40}$

A similar flow pattern was observed in the pulmonary artery with a systolic jet flanked by retrograde vortical flow along the vessel boundaries up- and downstream of the pulmonary valve throughout the entire systole (Figure 5). The systolic jet in the pulmonary artery had a more flat profile than the systolic jet of the ascending aorta, as described by others. ${ }^{41-43}$ Previous studies using MRI PC have shown retrograde flow late in systole in healthy volunteers and early in patients with pulmonary hypertension. ${ }^{41,42}$ None of the patients in this study had a history of pulmonary hypertension.

The finding of retrograde flow in early systole in the ascending aorta and pulmonary artery is probably a consequence of higher temporal and spatial resolution in the TO system compared with previously used modalities. ${ }^{38}$ Conventional Doppler US has a comparable temporal and spatial resolution with the TO method but is impaired by single range-gate and $1 \mathrm{D}$ velocity estimation, which obscure multidirectional flow. ${ }^{16}$

Secondary flow, generated by the twisting motion of the myocardium, the pulsatile nature of the flow pattern, and the curvature of the aortic arch, ${ }^{9,44}$ has been investigated with US, MRI, and computational fluid dynamics ${ }^{6,8,9,11,45,46}$ as well as vector flow US techniques. ${ }^{36,47}$ TO revealed for two examined patients a systolic clockwise secondary flow in ascending aorta as reported in other studies $6,36,45$ (Figure 3). Flow lines along with the calculated frequency of the rotation of 3.5 $\mathrm{Hz}$ found from the estimated vector velocities are calculated as described by Pedersen et al. ${ }^{36}$ Also the pulmonary artery was scanned in the short-axis view, which revealed short systolic vortices of both directions but primary clockwise, which previous studies confirm. ${ }^{37,42,43}$ The absence of secondary flow in diastole is probably a consequence of more chaotic diastolic flow patterns. However, even though the PRF was adjusted to $2 \mathrm{kHz}$ when recording secondary flow, the absence of diastolic secondary flow could be a consequence of velocities inferior to the threshold defined by the PRF setting.

For one patient, the right atrium was examined and a steady vortex was found in systole and diastole (Figure 6). This is consistent with previous studies, which showed a clockwise vortical flow direction going along the superficial wall toward the right ventricle and returning along the deep wall. ${ }^{1,48,49}$ A small part of the left atrium was also scanned, and a well-defined counterclockwise rotational flow was seen during systole and diastole (Figure 6). It has been argued that 
vortical and chiral flow streamlines in the cavities of the heart conserve energy and limit flow instability. ${ }^{48}$

The quantitative measurements obtained with $\mathrm{TO}$ of blood flow in the ascending aorta were compared with TEE, epiaortic conventional Doppler US, and PAC TD. The peak systolic velocities were lower when measured with TO compared with TEE and conventional Doppler US with a mean difference of $11 \%$ and $26 \%$, respectively (Table 1). Volume flow was likewise underestimated with TO compared with PAC TD with a difference of $16 \%$, while the difference of stroke volume was $10 \%$.

Previous validation studies have indicated that peak systolic velocities obtained with TO are underestimated in flow-rig settings and when compared with conventional spectral US. ${ }^{29,34}$ Udesen et al. found for transverse flow an underestimation of $10 \%$ and furthermore showed that the aliasing according to the Nyquist theorem of the axial velocity component is six times higher than the transverse velocity component. ${ }^{29,31}$ Pedersen et al. found $8 \%$ underestimation in peak systole and $27 \%$ overestimation in end diastole, and argued that relatively low temporal resolution and wall-filter settings contributed to the bias. ${ }^{34}$ The stroke volume calculated from vector velocities has been compared with MRI PC and a mean underestimation of 5\% was found. ${ }^{32,33}$

The differences between the quantitative measurements obtained with the different methods in this study are caused by several factors. Epiaortic scan directly on a beating heart obscured slow moving scatterers along vessel boundaries due to wall filtering. Moreover, it was seen in all three examined patients for some heartbeats that the axial velocity component aliased in peak systole. This aliasing was difficult to recognize during real-time scanning as the large transverse velocity component was nonaliased and therefore the overall direction mainly unaltered. Even though all measurements in comparison were acquired within 10 minutes, some variation must be expected. This can explain the difference between the TEE and epiaortic measurements and probably also a part of the difference between estimates of the reference methods and TO. The temporal resolution of the TO system of $15 \mathrm{~Hz}$ could have resulted in missed out peak systolic velocities and the inherent inaccuracies in the reference methods were probably also important confounders. ${ }^{50}$

The underestimation of stroke volume was partly due to underestimated velocities. However, the assumptions of circular geometry and rotationally symmetric flow also contributed to the bias. Hansen et al. showed that stroke volume calculated from long-axis 2D data had a mean variation of $24 \%$ particularly because of asymmetric flow. ${ }^{33}$ Also, it was difficult as a consequence of cardiac motion to secure scan exactly along the centerline of the vessel resulting in reduced lumen. Furthermore, it has been shown that stroke volume is a more stable variable to measure than cardiac output. ${ }^{51,52}$ For one patient, the difference of cardiac output was $16 \%$ while it was $10 \%$ for stroke volume, thus indicating a certain variation in flow and heart rate.

Some limitations of the TO method are important to mention. First, the scan depth is currently limited to $5 \mathrm{~cm}$, which implies that whole heart examination is not possible. To circumvent the scan depth limitation, the TO scans were in this study done directly on the heart. For one patient, the heart moved to such an extent that measuring of low velocities was impaired because of wall movement. Second, only 2D scan plane is achieved by TO so out-of-plane scatterer movement was not visualized.

The TO method is only available on the Pro Focus scanner using a $5 \mathrm{MHz}$ linear transducer. However, as the method uses a conventional pulse with only post-processing changed, it could potentially be implemented on other US systems. For evaluation of cardiac flow in adults, the only feasible approach with the current setup is during open-chest surgery with scanning directly on the heart. However, in newborns and babies, it is possible to evaluate cardiac flow on closed chest, due to shorter distance and cartilaginous costae. With the current setup, TO can potentially 
be used, for example, in evaluation of valve surgery in adults and congenital heart diseases in newborns and babies.

This work was carried out to investigate whether in vivo epicardiac examinations using TO were applicable. Through examination of three patients undergoing cardiac surgery, it was shown that the method can be used for qualitative and quantitative investigations of cardiac blood flow. The given measures are not a validation of TO when compared with TEE and conventional Doppler but a trial showing that further investigations using TO for velocity and volume flow estimation are warranted.

Using the TO method, the first real-time vector flow US estimation has been achieved of the complex blood flow in the cavities of the heart and great vessels of thorax. Several findings have previously been shown in other studies using mainly MRI PC estimations. However, due to the higher temporal and spatial resolution of the TO system, new information is presented in this study: (1) repeating cyclic flow patterns beat-to-beat with variation between patients in the ascending aorta and the pulmonary artery; (2) early systolic retrograde flow in the ascending aorta filling the aortic sinuses; (3) vortices in the aortic sinuses in diastole creating central antegrade flow; and (4) early systolic retrograde flow in the pulmonary artery.

\section{Conclusion}

TO vector flow estimation is a new tool to visualize and estimate cardiac blood flow. The angleindependent blood vector velocity method is unique compared with conventional imaging modalities in the ability to visualize complex flow patterns real time.

In this study, new insight into cardiac blood flow has been provided and it has been shown that quantitative measurements can be obtained from vector velocities. Future studies will follow the preliminary results given in this article, for example, aortic flow among healthy and valve-diseased patients, flow around the aortic valve before and after prosthetic valve insertion, and cardiac output validation. Other studies will concern examination of the basic fluid dynamics in the thoracic compartment, of fetal blood flow, on newborns with congenital heart conditions, on changes in cardiac blood flow during different kinds of interventions.

The TO technique may in the future be an important tool for cardiac blood flow measurements. Furthermore, when transducer setup limitations are solved, and TO is implemented on TEE, phased array, and 2D probes, new possibilities will emerge.

\section{Declaration of Conflicting Interests}

The author(s) declared no potential conflicts of interest with respect to the research, authorship, and/or publication of this article.

\section{Funding}

The author(s) received no financial support for the research, authorship, and/or publication of this article.

\section{References}

1. Kilner PJ, Yang GZ, Wilkes AJ, Mohiaddin RH, Firmin DN, Yacoub MH. Asymmetric redirection of flow through the heart. Nature. 2000;404(6779):759-61.

2. Bryant DJ, Payne JA, Firmin DN, Longmore DB. Measurement of flow with NMR imaging using a gradient pulse and phase difference technique. J Comput Assist Tomogr. 1984;8(4):588-93.

3. Firmin DN, Nayler GL, Klipstein RH, Underwood SR, Rees RS, Longmore DB. In vivo validation of MR velocity imaging. J Comput Assist Tomogr. 1987;11(5):751-6.

4. Mohiaddin RH, Yang GZ, Burger P, Firmin DN, Longmore DB. Automatic enhancement, animation, and segmentation of flow in peripheral arteries from MR phase-shift velocity mapping. J Comput Assist Tomogr. 1992;16(2):176-81. 
5. Nayler GL, Firmin DN, Longmore DB. Blood flow imaging by cine magnetic resonance. J Comput Assist Tomogr. 1986;10(5):715-22.

6. Bogren HG, Buonocore MH. 4D magnetic resonance velocity mapping of blood flow patterns in the aorta in young vs. elderly normal subjects. J Magn Reson Imaging. 1999;10(5):861-9.

7. Frydrychowicz A, Harloff A, Jung B, Zaitsev M, Weigang E, Bley TA, et al. 3-dimensional magnetic resonance flow analysis at $3 \mathrm{~T}$ : visualization of normal and pathological aortic vascular hemodynamics. J Comput Assist Tomogr. 2007;31(1):9-15.

8. Hope TA, Markl M, Wigstrom L, Alley MT, Miller DC, Herfkens RJ. Comparison of flow patterns in ascending aortic aneurysms and volunteers using four-dimensional magnetic resonance velocity mapping. J Magn Reson Imaging. 2007;26(6):1471-9.

9. Kilner PJ, Yang GZ, Mohiaddin RH, Firmin DN, Longmore DB. Helical and retrograde secondary flow patterns in the aortic arch studied by three-directional magnetic resonance velocity mapping. Circulation. 1993;88(5 Pt 1):2235-47.

10. Kim WY, Walker PG, Pedersen EM, Poulsen JK, Oyre S, Houlind K, et al. Left ventricular blood flow patterns in normal subjects: a quantitative analysis by three-dimensional magnetic resonance velocity mapping. J Am Coll Cardiol. 1995;26(1):224-38.

11. Markl M, Draney MT, Hope MD, Levin JM, Chan FP, Alley MT, et al. Time-resolved 3-dimensional velocity mapping in the thoracic aorta: visualization of 3-directional blood flow patterns in healthy volunteers and patients. J Comput Assist Tomogr. 2004;28(4):459-68.

12. Markl M, Harloff A, Bley TA, Zaitsev M, Jung B, Weigang E, et al. Time-resolved 3D MR velocity mapping at 3T: improved navigator-gated assessment of vascular anatomy and blood flow. J Magn Reson Imaging. 2007;25(4):824-31.

13. Steeds RP. Echocardiography: frontier imaging in cardiology. Br J Radiol. 2011;84(Spec Iss 3):S237-45.

14. American Society of A, Society of Cardiovascular Anesthesiologists Task Force on Transesophageal E. Practice guidelines for perioperative transesophageal echocardiography. An updated report by the American Society of Anesthesiologists and the Society of Cardiovascular Anesthesiologists Task Force on Transesophageal Echocardiography. Anesthesiology. 2010;112(5):1084-96.

15. Flachskampf FA, Badano L, Daniel WG, Feneck RO, Fox KF, Fraser AG, et al. Recommendations for transoesophageal echocardiography: update 2010. Eur J Echocardiogr. 2010;11(7):557-76.

16. Hansen KL. In-vivo studies of new vector velocity and adaptive spectral estimators in medical ultrasound. Dan Med Bull. 2010;57(5):1-23.

17. Jensen JA. Estimation of Blood Velocities Using Ultrasound: A Signal Processing Approach. New York: Cambridge University Press; 1996.

18. Bonnefous O. Measurement of the complete (3D) velocity vector of blood flows. Proc IEEE Ultrason Symp. 1988;795-9.

19. Fox MD. Multiple crossed-beam ultrasound Doppler velocimetry. IEEE Trans Son Ultrason. 1978;25:281-6.

20. Newhouse VL, Censor D, Vontz T, Cisneros JA, Goldberg BB. Ultrasound Doppler probing of flows transverse with respect to beam axis. IEEE Trans Biomed Eng. 1987;34:779-88.

21. Trahey GE, Allison JW, Ramm OT. Angle independent ultrasonic detection of blood flow. IEEE Trans Biomed Eng. 1987;34(12):965-7.

22. Nyrnes SA, Lovstakken L, Torp H, Haugen BO. Blood flow imaging - a new angle-independent ultrasound modality for the visualization of flow in atrial septal defects in children. Echocardiography. 2007;24(9):975-81.

23. Lovstakken L, Ibrahim KS, Vitale N, Henriksen ST, Kirkeby-Garstad I, Torp H, et al. Blood flow imaging: a new two-dimensional ultrasound modality for enhanced intraoperative visualization of blood flow patterns in coronary anastomoses. J Am Soc Echocardiogr. 2008;21(8):969-75.

24. Flynn J, Daigle RE, Pflugrath L, Linkhart K, Kaczkowski P. Estimation and display for vector Doppler imaging using planewave transmissions. Proc IEEE Ultrason Symp. 2011;413-8.

25. Pastorelli A, Torricelli G, Scabia M, Biagi E, Masotti L. A real-time 2-D vector Doppler system for clinical experimentation. IEEE Trans Med Imaging. 2008;27(10):1515-24.

26. Jensen JA. A new estimator for vector velocity estimation. IEEE Trans Ultrason Ferroelec Freq Contr. 2001;48:886-94. 
27. Jensen JA, Munk P. A new method for estimation of velocity vectors. IEEE Trans Ultrason Ferroelec Freq Contr. 1998;45:837-51.

28. Munk P. Estimation of the 2-D flow vector in ultrasonic imaging: a new approach. Master's thesis. Copenhagen: Technical University of Denmark; 1996.

29. Udesen J, Jensen JA. Investigation of transverse oscillation method. IEEE Trans Ultrason Ferroelec Freq Contr. 2006;53:959-71.

30. Hansen PM, Pedersen MM, Hansen KL, Nielsen MB, Jensen JA. New technology — demonstration of a vector velocity technique. Ultraschall Med. 2011;32(2):213-5.

31. Udesen J, Nielsen MB, Nielsen KR, Jensen JA. Examples of in vivo blood vector velocity estimation. Ultrasound Med Biol. 2007;33(4):541-8.

32. Hansen KL, Udesen J, Oddershede N, Henze L, Thomsen C, Jensen JA, et al. In vivo comparison of three ultrasound vector velocity techniques to MR phase contrast angiography. Ultrasonics. 2009;49(8):659-67.

33. Hansen KL, Udesen J, Thomsen C, Jensen JA, Nielsen MB. In vivo validation of a blood vector velocity estimator with MR angiography. IEEE Trans Ultrason Ferroelec Freq Contr. 2009;56(1):91-100.

34. Pedersen MM, Pihl MJ, Haugaard P, Hansen JM, Hansen KL, Nielsen MB, et al. Comparison of realtime in vivo spectral and vector velocity estimation. Ultrasound Med Biol. 2012;38(1):145-51.

35. De Backer D, Taccone FS, Holsten R, Ibrahimi F, Vincent JL. Influence of respiratory rate on stroke volume variation in mechanically ventilated patients. Anesthesiology. 2009;110(5):1092-7.

36. Pedersen MM, Pihl MJ, Hansen JM, Hansen PM, Haugaard P, Nielsen MB, et al. Arterial secondary blood flow patterns visualized with vector flow ultrasound. Proc IEEE Ultrasonics Symp. 2011;1242-5.

37. Barker AJ, Staehle F, Bock J, Jung BA, Markl M. Analysis of complex cardiovascular flow with threecomponent acceleration-encoded MRI. Magn Reson Med. 2012;67(1):50-61.

38. Markl M, Kilner PJ, Ebbers T. Comprehensive 4D velocity mapping of the heart and great vessels by cardiovascular magnetic resonance. J Cardiovasc Magn Reson. 2011;13:7.

39. Tortoli P, Bambi G, Guidi F, Muchada R. Toward a better quantitative measurement of aortic flow. Ultrasound Med Biol. 2002;28(2):249-57.

40. Kvitting JP, Ebbers T, Wigstrom L, Engvall J, Olin CL, Bolger AF. Flow patterns in the aortic root and the aorta studied with time-resolved, 3-dimensional, phase-contrast magnetic resonance imaging: implications for aortic valve-sparing surgery. J Thorac Cardiovasc Surg. 2004;127(6):1602-7.

41. Kondo C, Caputo GR, Masui T, Foster E, O'Sullivan M, Stulbarg MS, et al. Pulmonary hypertension: pulmonary flow quantification and flow profile analysis with velocity-encoded cine MR imaging. Radiology. 1992;183(3):751-8.

42. Bogren HG, Klipstein RH, Mohiaddin RH, Firmin DN, Underwood SR, Rees RS, et al. Pulmonary artery distensibility and blood flow patterns: a magnetic resonance study of normal subjects and of patients with pulmonary arterial hypertension. Am Heart J. 1989;118(5 Pt 1):990-9.

43. Sloth E, Houlind KC, Oyre S, Kim WY, Pedersen EM, Jorgensen HS, et al. Three-dimensional visualization of velocity profiles in the human main pulmonary artery with magnetic resonance phasevelocity mapping. Am Heart J. 1994;128(6 Pt 1):1130-8.

44. Nakatani S. Left ventricular rotation and twist: why should we learn? J Cardiovasc Ultrasound. 2011;19(1):1-6.

45. Koh TW, Parker KH, Kon M, Pepper JR. Changes in aortic rotational flow during cardiopulmonary bypass studied by transesophageal echocardiography and magnetic resonance velocity imaging: a potential mechanism for atheroembolism during cardiopulmonary bypass. Heart Vessels. 2001;16(1):1-8.

46. Tanaka M, Sakamoto T, Sugawara S, Nakajima H, Kameyama T, Katahira Y, et al. Spiral systolic blood flow in the ascending aorta and aortic arch analyzed by echo-dynamography. J Cardiol. 2010;56(1):97-110.

47. Hansen KL, Udesen J, Gran F, Jensen JA, Bachmann Nielsen M. In-vivo examples of flow patterns with the fast vector velocity ultrasound method. Ultraschall Med. 2009;30(5):471-7.

48. Kilner PJ, Yang GZ, Firmin DN. Morphodynamics of flow through sinuous curvatures of the heart. Biorheology. 2002;39(3-4):409-17. 
49. Wong KK, Kelso RM, Worthley SG, Sanders P, Mazumdar J, Abbott D. Cardiac flow analysis applied to phase contrast magnetic resonance imaging of the heart. Ann Biomed Eng. 2009;37(8):1495-515.

50. Hoskins PR. A review of the measurement of blood velocity and related quantities using Doppler ultrasound. Proc Inst Mech Eng H. 1999;213(5):391-400.

51. Higginbotham MB, Morris KG, Williams S, McHale PA, Coleman RE, Cobb FR. Regulation of stroke volume during submaximal and maximal upright exercise in normal man. Circ Res. 1986;58:281-91.

52. Lewis JF, Kuo LC, Nelson JG, Limacher MC, Quinones MA. Pulsed Doppler echocardiographic determination of stroke volume and cardiac output: clinical validation of two new methods using the apical window. Circulation. 1984;70(3):425-31. 